\title{
Health Literacy Levels among Outpatients at a Tertiary Hospital in Delhi, India
}

Monika Sahoo,' Charu Kohli,' Jugal Kishore. ${ }^{1}$

\begin{abstract}
Background: Health literacy is defined as the cognitive and social skills which determine the motivation and ability of individuals to gain access to, understand, and use information in ways which promote and maintain good health. This study was conducted to determine health literacy levels and the associated factors among patients attending the outpatient departments of a tertiary care hospital in Delhi. Methods: A hospital-based cross-sectional study was carried out in a tertiary care teaching hospital in Delhi over a period of four months. A total of 150 patients were included in the study. Fifty patients from the Diabetes Clinics, 50 patients from Hypertension Clinics, and 50 patients with anemia from the Antenatal Outpatient Department (OPD) were selected using a convenience sampling method. Data was analyzed using Epi Info software. Statistical analysis was conducted with the chi-square test and the Fisher's exact test. P values less than 0.05 were considered significant. Results: Out of 50 diabetic subjects, 37 (74\%) understood the information about their blood sugar levels as explained to them by the doctor. Similar results were found among hypertensive subjects as well. Furthermore, education status was significantly associated with health literacy. In terms of understanding the regimen of medications, significant association was seen with age, sex, and education. Conclusion: Education status, age, and gender are important determinants of health literacy. Our results support that innovative strategies of communication should be used to improve health literacy among patients.
\end{abstract}

Keywords: Health Literacy, Knowledge, Outpatient Clinics, Diabetes Mellitus, Hypertension (Source: MeSH-NLM).

About the Author: Monika Sahoo has completed her internship for the MBBS undergraduate program at Maulana Azad Medical Co llege, New Delhi, India.
Submission: Feb 9, 2015

Acceptance: Mar 24, 2015

Publication: Mar 31, 2015

Process: Peer-reviewed

\section{Introduction}

The World Health Organization (WHO) defines health literacy as cognitive and social skills that determine the motivation and ability of people to understand, gain access and use the information to obtain good health. By improving people's access to health information and their capacity to use it effectively, health literacy is critical to empowerment (WHO. Available from: http://www.who.int/healthpromotion/conferences/7gchp/track2/en/, cited 2015 Jan 02).

Health literacy includes an individual's ability to understand instructions and other health related documents. Examples include instructions written on drugs, appointment slips, information brochures, physicians' advice on drug schedules, counseling, compliance, and the ability to utilize and negotiate health-care systems.'

Among the different barriers to utilization of health care services like financial issues, lack of access to health providers and inadequate preventive care, low health literacy is one of the most important factors. ${ }^{2}$ Improved health literacy develops competencies for the individual to assimilate, comprehend, and adapt to healthy practices and reduce risky behaviors. ${ }^{3}$ Several studies have shown that low health literacy is associated with higher rates of mortality and lack of preventive behaviors such as screening tests.,5 These patients are more likely to indulge in high-risk behaviors. Low health literacy generally relates to poor physical and mental health. 6,7 Studies have shown that low health lite- racy, in terms of poor understanding of medical information, may lead to poor self-adherence to drugs and higher propensity to have non-communicable diseases risk factors (tobacco use, hospitalizations, and substance abuse). ${ }^{8-11}$

Keeping the above in mind, it is important to gain an understanding of health literacy rates among patients in India. It is important to study this topic because a number of factors play a role in health, health seeking behaviors, and compliance. This topic is especially relevant in an Indian context where cultural factors play a crucial role in both health and disease. An understanding of health literacy may help to plan future strategies to improve general health care. This study was conducted with an objective to determine health literacy rates and the associated factors among patients attending the outpatient clinics of a tertiary care hospital in Delhi.

\section{Methods}

A cross-sectional study was conducted in a tertiary care teaching hospital in Delhi over a period of four months. All patients attending Medicine and Obstetrics Outpatient Department (OPDs) in the hospital constituted the study population.

The sample size was calculated on the basis of findings of a previous study that assessed the mean score for health literacy in outpatient clinics in India. ${ }^{3}$ Taking $95 \%$ confidence intervals and an alpha error of $5 \%$, the sample size was calculated to be 102. However, a total of 150 patients were included in the study.

${ }^{1}$ Maulana Azad Medical College, New Delhi, India. 
Fifty patients in each of Diabetes and Hypertension clinics in the Department of Medicine and 50 patients with anemia from the Antenatal OPD in the Obstetrics Department were selected by a convenience sampling method. All adult patients aged 18 years or older who gave consent to participate in the study were included. Patients who were seriously ill, needed urgent medical attention and required admission were excluded.

The reason for choosing the conditions was the increasing trend of non-communicable diseases in urban areas in India. Anemia was chosen as the topic for antenatal patients since the prevalence of anemia is high in pregnancy in India. Anemia is also one of the important causes of maternal morbidity and mortality in India. Thus, an understanding of these diseases may be helpful for future policy decisions in public health in relation to health literacy.

A pretested, predesigned, semi-structured questionnaire consisting of eleven items on demographic characteristics like age, sex, educational status, and occupation was developed. Education status was broadly grouped into formal and informal education. Similarly, occupational status was divided into unemployed and employed. The health literacy among study subjects was assessed using the questionnaire and included the patients' level of understanding of their illness and the interpretation of the numeric values related to their illness as told to them by the health care provider and as indicated by various investigations.

The questionnaire was pilot tested in a different setting among patients for assessing its feasibility and reliability. Suitable modifications were done afterwards. Cronbach's alpha, which is a coefficient of internal consistency, was calculated to be 0.82 . Experts in relevant fields were also asked about their opinion during the development of the questionnaire. The documents related to the investigations, diagnosis, and prescription of medications were also examined by the researcher to validate the accuracy of information provided by study subjects such as the dose of medications being taken and the value of hemoglobin. The subjects were interviewed, maintaining privacy by the researcher, in their local language, and it took 10-12 minutes to complete each interview.
Data collected was analyzed using Epi-Info software. The results were presented in mean \pm standard deviation (SD) and proportions wherever relevant. Any difference between two proportions was assessed by a chi-square test for normal distributions and the Fisher exact test for non-normal distributions of data. P-values less than 0.05 were considered significant. Patient data confidentiality was maintained throughout the study. Written informed consent was obtained from all participants. Institutional ethical clearance was also obtained.

\section{Results \\ Socio-Demographic Characteristics}

Out of 50 subjects who were diabetic, $41(82 \%)$ were more than 45 years of age. Out of the 50 subjects who were hypertensive, $18(36 \%)$ were above the age of 60 years, while among 50 female subjects from the antenatal clinic, 45 ( $90 \%)$ were in the age group of 15 to 30 years old. Among the diabetic subjects, 32 $(64 \%)$ were males and $18(36 \%)$ were females. Among hypertensive subjects, $28(56 \%)$ were males and $22(44 \%)$ were females. Small percentages of diabetics (10\%) and hypertensive patients ( $14 \%$ ) and about one-third of obstetric OPD patients (30\%) reported that they had not received any formal education. Out of 50 diabetic subjects, 7 (14\%) were unemployed. Among the 50 hypertensive subjects, $10(20 \%)$ were unemployed while 35 (70\%) of the anemic subjects were unemployed (Table 1).

\section{Health Literacy among Diabetic Subjects}

Out of the 50 diabetic subjects, $74 \%$ understood the significance of the information about their blood sugar level as explained by the doctor. For example, patients were asked details such as what the normal range of blood sugar levels is and what was the target for blood sugar levels set for them by their doctor for optimum control. Twenty-six percent of participants did not understand the same. However, no significant difference was found between various age groups $(p=0.21)$. Similarly, no association was seen with occupation status and gender ( $p>0.05$ ). There was a difference in those who did not receive any formal education (20.0\%) and those who had received formal education $(80.0 \%)$ in terms of their understanding of the information given to them by their healthcare provider. This difference was statistically significant $(p=0.01)$, as shown in Table 2 .

Table 1. Socio-Demographic Characteristics of Study Subjects.

\begin{tabular}{|c|c|c|c|c|}
\hline Characteristic & $\begin{array}{l}\text { Diabetes Mellitus OPD* } \\
\quad \mathrm{n}=50[\text { freq(\%) }]\end{array}$ & $\begin{array}{c}\text { Hypertension OPD } \\
\mathrm{n}=50[\text { freq }(\%)]\end{array}$ & $\begin{array}{l}\text { Obstetrics OPD } \\
\mathrm{n}=50[\text { freq }(\%)]\end{array}$ & $\begin{array}{c}\text { Total } \\
\mathrm{N}=150[\text { freq }(\%)]\end{array}$ \\
\hline \multicolumn{5}{|l|}{ Gender } \\
\hline Male & $32(64)$ & $28(56)$ & $0(0)$ & $60(40)$ \\
\hline Female & $18(36)$ & $22(44)$ & $50(100)$ & $90(60)$ \\
\hline \multicolumn{5}{|l|}{ Age (in years) } \\
\hline Less than 45 & $9(18)$ & $16(32)$ & $45(90)$ & $70(46.7)$ \\
\hline More than 45 & $41(82)$ & $34(68)$ & $5(10)$ & $80(53.3)$ \\
\hline \multicolumn{5}{|l|}{ Education status } \\
\hline No formal education & $5(10)$ & $7(14)$ & $15(30)$ & $27(18)$ \\
\hline Formal education & $45(90)$ & $43(86)$ & $35(70)$ & $123(82)$ \\
\hline \multicolumn{5}{|l|}{ Occupation } \\
\hline Unemployed & $7(14)$ & $10(20)$ & $35(70)$ & $52(34.7)$ \\
\hline Employed & $43(86)$ & $40(80)$ & $15(30)$ & $98(45.3)$ \\
\hline
\end{tabular}


Table 2. Associates of Health Literacy in Diabetes and Hypertension Outpatient Department.

\begin{tabular}{|c|c|c|c|c|}
\hline Characteristic & $\begin{array}{l}\text { Diabetes OPD* } \\
n=37 \text { [freq(\%)] }\end{array}$ & $P$ value & $\begin{array}{l}\text { Hypertension OPD } \\
n=38 \text { [freq(\%)] }\end{array}$ & $P$ value \\
\hline \multicolumn{5}{|l|}{ Gender } \\
\hline Male & $23(62.2)$ & $0.74^{+}$ & $19(50)$ & 0.12 \\
\hline \multicolumn{5}{|l|}{ Age (in years) } \\
\hline Less than 45 & $5(13.5)$ & $0.21^{+}$ & $11(28.9)$ & $0.48^{+}$ \\
\hline More than 45 & $32(86.5)$ & & $27(71.1)$ & \\
\hline \multicolumn{5}{|l|}{ Education status } \\
\hline No formal education & $1(2.7)$ & $0.01^{+}$ & $0(0)$ & $0.01^{\dagger}$ \\
\hline Employed & $32(86.5)$ & & $32(84.2)$ & \\
\hline
\end{tabular}

Legend: * OPD - Outpatient Department. ${ }^{\dagger}$ Fisher exact test was used.

Questions were asked about the patient's understanding of the regimen of taking anti-diabetic medications. Eighty-four percent of the subjects reported that they understood the regimen as explained to them by the doctor. Among subjects less than 45 years, $44.4 \%$ said that they understood the regimen as told to them but this figure was $92.7 \%$ among subjects aged more than 45 years $(p=0.01)$. Among subjects with no formal education, not a single subject understood this information, while among those with formal education, $93.3 \%$ were able to comprehend the information $(\mathrm{p}=0.01)$. Similarly, among occupational classes, only $11.9 \%$ of those patients who were unemployed understood the regimen; $88.1 \%$ of those who were employed understood the regimen. This was not statistically significant $(p=0.31)$. A significantly higher proportion of females $(100 \%)$ than males $(75 \%)$ understood the information about their regimen $(p=0.03)$.

\section{Health Literacy among Hypertensive Subjects}

Among subjects from the Hypertension Clinic, none among those with no formal education understood information about the blood pressure (i.e. normal values of blood pressure) and their target blood pressure levels as told to them by their doctor. Among those who had received formal education, $88.4 \%$ understood this information. This difference with respect to education status was statistically significant $(p=0.01)$. A lower proportion of unemployed subjects understood the same information as compared to employed. This was not statistically significant $(p=0.22)$. No difference was seen between gender and age groups (Table 2).

About $60 \%$ of study subjects reported that they understood the regimen of taking antihypertensive medications, including dosage, frequency, and side effects, as explained to them by their doctor. Among subjects less than 45 years old, $18.8 \%$ said they understood the regimen. This figure, however, was $79.4 \%$ among subjects aged more than 45 years old and represented a significant difference $(p=0.01)$. Among those with no formal education, not even a single subject understood the information whereas among other groups with formal education training, $66.7 \%$ were able to understand the regimen $(p=0.01)$. There was no significant difference seen in occupation. A significantly higher proportion of females $(100 \%)$ than males $(28.6 \%)$ understood the regimen $(p=0.01)$.

\section{Health Literacy among Anemic Subjects}

In anemic subjects in obstetrics OPD, significant differences were observed between those educated formally and those who were not in terms of the understanding of the value of hemoglobin $(p=0.01)$. Among occupational classes, $57.1 \%$ of those who were employed were able to understand the level of hemoglobin while $42.9 \%$ of those who were unemployed understood the same $(\mathrm{p}=0.34)$ (Figure 1).

Seventy percent of the subjects reported that they understood the regimen of taking drugs given to them for the treatment of anemia as explained by their doctor. Among subjects who received formal education, $73.3 \%$ understood the information about the regimen whereas among those who had not received formal education, $68.6 \%$ were able to understand the same. This difference was not statistically significant $(p=0.73)$. There was no significant difference between occupation status.

Figure 1. Associates of Health Literacy in Antenatal Obstetrics Outpatient Departments.

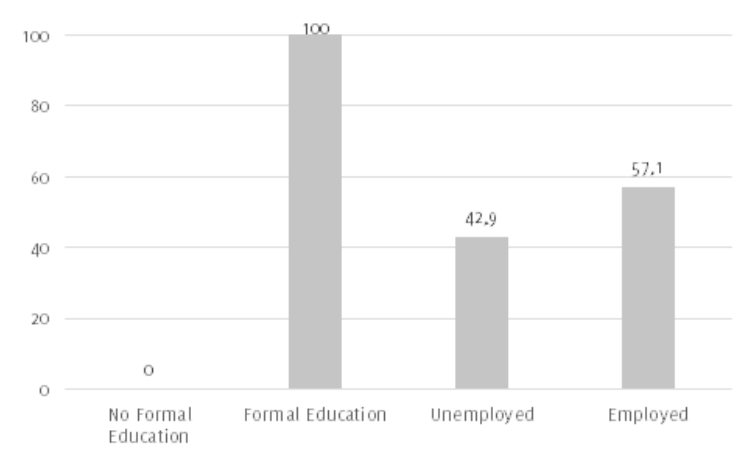

Legend: Fisher exact test was used; P value $<0.05$ for education status. 


\section{Discussion}

The present study demonstrated that health literacy varies among education classes where those with formal education have health literacy rates higher than other groups. Furthermo$\mathrm{re}$, these same individuals had better understanding of their illnesses. Similar findings were mentioned by Howard DH, et al., in 2006 where having a high school degree was significantly associated with health literacy and higher likelihood of good self-reported health. ${ }^{12}$ However, significant differences were seen in certain age groups, genders, occupational classes, and with education in terms of patients understanding the regimen of medications explained to them by their doctor. This is an important aspect because it has been shown that the clarity of doctor's explanations was associated with patient understanding of care and self-efficacy. ${ }^{13}$ Moreover, poor health literacy is found to be associated with worse glycemic control and a higher risk of complications. ${ }^{14}$

Among patients with hypertension, significant differences were present depending on the education status of subjects. Similarly, unemployed patients also had lesser understanding of the information provided by clinicians. These results are similar to those reported by Levinthal BR, et al., among hypertensive patients where health literacy was associated with education status. ${ }^{15}$ Similarly, in diabetic patients, significant differences were seen among age groups, education classes, and occupation statuses in terms of the understanding of the regimen related to taking medications. Significantly more females than males reported to have understood the regimen. This is different from findings observed by Javadzade SM, et al., in their study conducted in Iran where subjects with low health literacy tend to be older, had fewer years of schooling, and were females. The reason for this discrepancy may be differences in the study population and socio-demographic characteristics in these two studies. ${ }^{16}$ Another factor could be the number of visits to OPD, which can be confounded by gender.

For patients with anemia, significant differences were seen with education status. This is an important aspect when looking at the burden of anemia in pregnancy in India and its consequences. Studies have shown that women with adequate health literacy have significant differences in initiation and frequency of antenatal care, neonatal birth weight, maternal hematocrit, ferrous and folic acid tablet consumption, pregnancy weight gain, gestational age at birth, method of delivery, and duration of breastfeeding. ${ }^{17}$ Low health literacy has its implications on patients' understanding of health messages and limits their ability to care for their medical problems..$^{18}$ It is also an independent risk factor for hospital admission and it is associated with higher morbidity and more healthcare utilization. ${ }^{19,20}$

This study provides the first insight into health literacy and its determinants in an Indian setting. It suggests important policy implications for the future in terms of the training of health professionals in communication skills. Non-random sampling is one of the limitations of this study, but important points of concern are well understood.

India is a country with a huge population burden. The country has challenges of tackling the dual burden of communicable and non-communicable diseases. As per Global Status Report on non-communicable diseases (NCDS) by WHO for the year 2014, the figures for India for premature NCD mortality rate and number of deaths due to NCDs are higher than other countries (WHO. Available from: http://apps.who.int/iris/bitstre am/10665/148114/1/9789241564854_eng.pdf, cited 2015 Jan 02). Such scenarios do not present a promising picture for the future. Health literacy is now believed to be an important determinant of health, one that intersects with other determinants in a myriad of ways. Although health literacy is not the only pathway to better health outcomes, it is certainly an important avenue. Therefore, any effort to improve health outcomes should take into account the health literacy of the patient. For effective disease management and maintenance of health, one must be able to understand, interpret, and act on health information, whether it is communicated verbally or in written form. ${ }^{21}$ Health literacy is certainly going to impact the health status of the country with its crucial role in prevention and control of diseases. Association of health literacy with education is an important finding for advocacy to improve the educational status of the country.

It can be concluded from this study that education status, age, and gender are all important associates of health literacy. Healthcare providers should be aware of these factors when dealing with patients in their OPD for effective communication. Furthermore, innovative strategies should be used to improve the levels of health literacy among patients. 


\section{References}

1. Wehmeyer MM, Corwin CL, Guthmiller JM, Lee JY. The impact of oral health literacy on periodontal health status. J Public Health Dent. 2014 Winter; $74(1): 80-7$.

2. Devi MA, Soni S, Radha, Kadanakuppe S, Nagashree, Pallavi. Reliability and validity of a questionnaire to assess oral health literacy among college students in Bangalore city. Int J Contemp Dent. 2011 Mar;2(2):43-7.

3. Haridas R, Supreetha S, Ajagannanavar SL, Tikare S, Maliyil MJ, Kalappa AA. Oral health literacy and oral health status among adults attending dental college hospital in India. J Int Oral Health. 2014 Nov-Dec;6(6):61-6.

4. Baker DW, Wolf MS, Feinglass J, Thompson JA, Gazmararian JA, Huang J. Health literacy and mortality among elderly person. Arch Intern Med. 2007 Jul 23;167(14):1503-9.

5. White S, Chen J, Atchison R. Relationship of preventive health practices and health literacy: a national study. Am J Health Behav. 2008 MayJun;32(3):227-42.

6. Wolf MS, Gazmararian JA, Baker DW. Health literacy and health risk behaviors among older adults. Am J Prev Med. 2007 Jan;32(1):19-24.

7. Wolf MS, Gazmararian JA, Baker DW. Health literacy and functional health status among older adults. Arch Intern Med. 2005 Sep 26;165(17):1946-52.

8. Caplan L, Wolfe F, Michaud K, Quinzanos I, Hirsh J M. Strong association of health literacy with functional status among rheumatoid arthritis patients: a cross-sectional study. Arthritis Care Res (Hoboken). 2014 Apr;66(4):508-14. 9. Marrie RA, Salter A, Tyry T, Fox RJ, Cutter GR. Health literacy association with health behaviors and health care utilization in multiple sclerosis: a cross-sectional study. Interact J Med Res. 2014 Feb 10;3(1):e3.

10. Morrison AK, Schapira MM, Gorelick MH, Hoffmann RG, Brousseau DC. Low caregiver health literacy is associated with higher pediatric emergency department use and nonurgent visits. Acad Pediatr. 2014 May-Jun;14(3):309-14. 11. Reavley NJ, McCann TV, Cvetkovski S, Jorm AF. A multifaceted intervention to improve mental health literacy in students of a multicampus university: a cluster randomised trial. Soc Psychiatry Psychiatr Epidemiol. 2014 Oct;49(10):1655-66. 12. Howard DH, Sentell T, Gazmararian JA. Impact of health literacy on socioeconomic and racial differences in health in an elderly population. J Gen Intern Med. 2006 Aug;21(8):857-61.

13. Inoue M, Takahashi M, Kai I. Impact of communicative and critical health literacy on understanding of diabetes care and self-efficacy in diabetes management: a cross-sectional study of primary care in Japan. BMC Fam Pract. 2013 Mar 23;14:40.

14. Souza JG, Apolinario D, Magaldi RM, Busse AL, Campora F, Jacob-Filho W. Functional health literacy and glycaemic control in older adults with type 2 diabetes: a cross-sectional study. BMJ Open. 2014 Feb 12;4(2):e004180.

15. Levinthal BR, Morrow DG, Tu W, Wu J, Murray MD. Cognition and health literacy in patients with hypertension. J Gen Intern Med. 2008 Aug;23(8):1172-6. 16. Javadzade SH, Sharifirad G, Radjati F, Mostafavi F, Reisi M, Hasanzade A. Relationship between health literacy, health status, and healthy behaviors among older adults in Isfahan, Iran. J Educ Health Promot. 2012;1:31.

17. Kohan S, Chasemi S, Dodangeh M. Associations between maternal health literacy and prenatal care and pregnancy outcome. Iran J Nurs Midwifery Res. 2007 Autumn;12(4):146-52.

18. van Onna $M$, Hinsenveld $E$, de Vries $H$, Boonen A. Health literacy in patients dealing with gout: a qualitative study. Clin Rheumatol. 2014 Dec 12. [Epub ahead of print]

19. Ownby RL, Acevedo A, Jacobs RJ, Caballero J, Waldrop-Valverde D. Quality of life, health status, and health service utilization related to a new measure of health literacy: FLIGHT/VIDAS. Patient Educ Couns. 2014 Sep;96(3):404-10. 20. Bostock S, Steptoe A. Association between low functional health literacy and mortality in older adults: longitudinal cohort study. BM]. 2012 Mar 15;344:e1602.

21. D'Cruz AA, Shankar Aradhya MR. Health literacy among Indian adults seeking dental care. Dent Res J (Isfahan). 2013 Jan;10(1):20-4.

\section{Acknowledgments}

This project was completed as a part of short term studentship by the first author from the Indian Council of Medical Research (ICMR). The support is greatly acknowledged by the authors.

Conflict of Interest Statement a Funding

The Authors have no funding, financial relationships or conflicts of interest to disclose.

\section{Author Contributions}

Conception and design the work/idea: MS, JK. Collect data/obtaining results: MS. Analysis and interpretation of data: MS, JK. Write the manuscript: MS, CK. Critical revision of the manuscript: CK, JK. Approval of the final version: MS, CK. Contribution of patients or study material, Statistical advice: CK. Administrative or technical advice: JK.

Cite as:

Sahoo M, Kohli C, Kishore J. Health Literacy Levels among Outpatients at a Tertiary Hospital in Delhi, India. Int J Med Students. 2014 Nov2015 Mar;3(1):29-33. 